\title{
Contextualising social capital in online brand communities
}

\author{
Stephanie Meek ${ }^{1}$ (1) $\cdot$ Madeleine Ogilvie $^{1} \cdot$ Claire Lambert $^{1} \cdot$ Maria M. Ryan $^{1}$
}

Revised: 7 February 2018/Published online: 17 December 2018

(C) The Author(s) 2018

\begin{abstract}
Online brand communities (OBC) are growing in number and becoming an increasingly important interface where marketers can effectively facilitate the relationship between their brand and consumers. A qualitative study using a four-month netnography over three OBCs followed by focus groups with OBC members explored the dynamics of social capital in these communities. Findings indicate that social capital is an important driver in the success of OBCs, and all the elements of social capital including a shared language, shared vision, social trust and reciprocity are evident. Moreover, results from this study indicate that these elements are crucial in developing the network ties that are integral to building loyalty and brand equity.
\end{abstract}

Keywords Online brand communities · Social capital · Network ties

\section{Introduction}

In an internationally competitive market, a company's brand is its most valuable asset and increasing and retaining loyal customers is key to long-term success. Forging binding relationships between consumers and their brand is therefore of critical importance to most organisations (Lhotáková 2012). Previous studies indicate that online brand communities (OBCs) effectively facilitate such relationships (Backhaus et al. 2011; Madupu and Cooley

Stephanie Meek

s.meek@ecu.edu.au

1 School of Business and Law, Edith Cowan University, 270 Joondalup Drive, Joondalup, WA 6027, USA
2010) and provide companies with reliable marketing intelligence to potentially gain a competitive advantage.

OBCs are online forums dedicated to a specific brand, where consumers gather, exchange information and socialise. Today they are more prevalent than ever before, yet research in this area is still limited. OBCs empower members to support each other and visitors to the community (Islam et al. 2018; Millán and Díaz 2014). For example, successful OBCs such as the Apple Forum (Apple Support Communities 2018) connects Apple users from around the world and they share experiences and discuss products with like-minded others. The very popular LEGO community (LEGO Ideas Community 2018) is a platform for LEGO enthusiasts to share novel ideas for new LEGO sets, share experiences and socialise. The LEGO Corporation overtly seeks and harnesses consumer innovations and co-creation of new products through the LEGO online brand community. In this case, the OBC is an effective cocreative brand partner (Schau et al. 2009). The "Find a Nike + Run Club (2018) provides encouragement, guidance and support for runners. The brand stories created and shared by users through these OBCs influence not only existing brand community members but also new ones, who become reassured in their perceptions and expectations of the brand with their involvement and gain trust towards the brand in the process (Islam et al. 2018; Singh and Sonnenburg 2012).

Many consumers purchase brands they perceive as selfrepresentative, they are also "likely to identify more strongly with brand websites as communities and, as a result, to interact online with firms and each other at the highest levels" (Alden et al. 2016, p. 5909). It is the ongoing creation of user-generated content that sustains the life of an OBC (Baldus et al. 2015; Kamboj and Rahman 2017). Furthermore, this rich online interaction not only 
creates a sense of belonging between members in the community, it deepens the bond between the consumer and the brand, resulting in positive outcomes such as brand loyalty, brand usage and brand recommendation (Loureiro et al. 2017). According to Kamboj and Rahman (2017, p. 307) "The key challenge for any online brand community provider is to encourage participation and to create a thriving community".

The relational structure of a social group has the potential to provide benefits of social value to both the individuals in the group, and the group as a whole. This phenomenon forms the basis of social capital theory (Bourdieu 1986; Coleman 1988; Nahapiet and Ghoshal 1998). Social capital is often used to refer to the characteristics of a society or community that encourages cooperation amongst members in the group to achieve a common goal such as increased productivity or knowledgesharing efficiency (Hau et al. 2013; Jones and Taylor 2012; Nahapiet and Ghoshal 1998).

Fundamentally social capital exists in the pattern of links between people in a group, their shared values and understandings, and their social trust, all of which enable them to work together more efficiently (Coleman 1988; Granovetter 1992; Jones and Taylor 2012; Nahapiet and Ghoshal 1998; Watson and Papamarcos 2002). Social capital can be defined as "the features of social organisation-networks, norms and trust - that enable people to act together more effectively to pursue shared objectives" (Putnam 2000).

The primary benefit of communities in general with an accrued level of social capital is the ability to effectively disperse information between members of the community (Adler and Kwon 2002; Nahapiet and Ghoshal 1998). This is especially relevant in $\mathrm{OBCs}$ as they rely on the interaction between members in the form of brand-related knowledge sharing for their ongoing survival (Alden et al. 2016: Kamboj and Rahman 2017; Wirtz et al. 2013). Consequently, understanding the facets of social capital and how they influence consumer behaviour is crucial for practitioners when developing strategies for communication and co-creative relationships with their consumers.

Although an abundance of prior literature investigates social capital in offline and online communities, research shows OBCs are a unique type of online community with distinct features that differentiate them from online groups in general (Baldus et al. 2015). Members of OBCs exhibit a consciousness of kind, shared rituals and traditions, and moral responsibility based on their affinity with a specific brand (Muniz and O'Guinn 2001). Members also have a psychological attachment and strong emotional bond with the brand that shapes their behaviour in the community (Baldus et al. 2015; Kamboj and Rahman 2017).
The lack of attention given to the facets of social capital as a multidimensional construct specific to an OBC environment highlights a significant gap in the literature. Therefore, the aim of this study is to explore the elements of social capital within the context of OBCs and given the benefits derived from social capital, gain insights into the key drivers of their success.

To explore these issues, we conducted an exploratory qualitative study of online brand communities addressing the following two research questions:

1. What are the elements that embody the social capital construct in an online brand community context?

2. What are the potential benefits of social capital in online brand communities?

\section{Theoretical background}

\section{Online brand communities (OBC)}

An OBC is a "specialized, non-geographically bound community, based on a structured set of social relationships among users of a brand" (Muniz and O'Guinn 2001, p. 412). Although this is only one of many definitions that exist throughout the literature, they all have a common theme that suggests OBCs are characterised by the nature or quality of the interactive behaviour that occurs in the community. For example, Muniz and O'Guinn (2001) propose markers of a true brand community including consciousness of kind, shared rituals and traditions, and moral responsibility differentiates a collection of people in a group setting from a "community", and without these essential attributes, a group cannot call itself a genuine community.

In brand-focused communities such as OBCs, consciousness of kind refers to the collective sense of belonging that members feel towards the community and each other. They have a shared understanding of what the brand represents. This differentiates them from users who do not have the same connection with the brand and from users of other brands (Muniz and O'Guinn 2001). There is a feeling of common meaning amongst members through their shared interest in the brand (Alden et al. 2016; Zhang and Luo 2016). Shared rituals and traditions relate to the perpetuation of the history and meaning of the brand, demonstrated by the shared behavioural norms of the community. The sharing of brand-related stories and information reinforces the bond between members and the social solidarity of the community (Algesheimer et al. 2005; Muniz and O'Guinn 2001). A moral responsibility is a direct consequence of the shared attitude and communal 
values members exhibit in OBCs. It is the sense of obligation and duty that members feel towards individuals in the group and the community as a collective (Muniz and O'Guinn 2001). Communities that exhibit a moral responsibility give members the confidence to seek assistance from each other in their consumption behaviour. This is an important attribute of OBCs as reciprocal behaviour is key to the efficient flow of brand information between members (Islam et al. 2018).

Also, of relevance to OBCs is the Usability and Sociability framework (Preece 2001) which assumes that the ease with which a site is navigable or how socially interactive a virtual community is, determines its success. The Usability and Sociability theory (Preece 2001) proposes that the perceived level of usability and sociability is positively related to continuous participation in the community, an outcome widely acknowledged as a critical success factor for OBCs ( $\mathrm{Lu}$ et al. 2011). In a virtual community, usability refers to a structure that enables users to navigate around the site and easily find what they are looking for, with the assistance of tools to make communication stress-free and the presentation of information easy to follow (De Souza and Preece 2004; Preece 2002).

Sociability refers to encouraging reciprocity and the social norms that keep members on topic and less likely to post offensive comments. It is associated with the kind of social environment that motivates interaction between members, as indicated by the social aspect of the Usability and Sociability framework to define the characteristics critical to the success of online communities (Preece 2001). These attributes can be distinguished by their functional or hedonistic qualities and include elements such as purpose, people, policy, dialogue and social interaction, information design, navigation and access. These attributes can then be categorised further as functional or social benefits.

By their very nature, theories are open to interpretation and the Usability and Sociability framework is no exception. Preece (2001) was herself one of the first to suggest that the attributes of successful online communities, as indicated in the framework, differ depending on the purpose or function of the community. For example, there is likely to be a greater need for the sociability dimension in communities that rely on social interaction such as OBCs, as compared with communities of practice where the usability attributes that improve functionality will be of greater importance (Preece 2001).

According to Sicilia and Palazon (2008), OBCs in general are more valued for their social support and entertainment appeal than the informational benefits they provide. However, this may be related to the types of communities in question. For example, an $\mathrm{OBC}$ based around a technical product, such as Apple computers (Shang et al. 2006), will attract members who are looking for specific information about technical issues, whereas a leisure-based community is likely to generate more social discussion (Dholakia et al. 2004). Others argue whilst participation is initially driven by the need to gather information ( $\mathrm{Lu}$ et al. 2011; Shah 2006), long-term participation is predicated on a combination of hedonic motivations, such as enjoyment and developing strong network ties in addition to the information the community provides (Fang and Neufeld 2009).

A fundamental characteristic of OBCs is that they provide businesses with a platform to generate unparalleled consumer engagement, loyal customer relationships and reliable marketing intelligence (Brodie et al. 2013; Cova et al. 2015; Mathwick et al. 2008; McAlexander et al. 2002; Shang et al. 2006; Sicilia and Palazón 2008). Anderson (2005) suggests consumers who take the time and effort to participate in community-run activities or share information through posts are more likely to build long-term relationships amongst themselves and with the company. This leads to an increase in brand loyalty behaviours.

For example, several well-known and respected organisations such as Apple (Muniz and Schau 2005), HarleyDavidson (Schouten and McAlexander 1995), Jeep (McAlexander et al. 2002) and Saab (Muniz and O'Guinn 2001) have successfully increased the number of loyal advocates to their brands through relationship-building activities. Their success gives credence to the notion that OBCs have the propensity to provide genuine opportunities for companies to influence members and increase the number of loyal consumers of their particular brand (Andersen 2005; Kuo and Feng 2013; Muniz and Schau 2005).

The main objective of an online community is to bring people together and to facilitate member interaction (Fournier and Avery 2011). An OBC provides a platform where consumers can share opinions, thoughts and knowledge, and where they can exchange brand information (Mahrous and Abdelmaaboud 2017; Sloan et al. 2015). Web 2.0 has enabled a switch from Internet-enabled delivery of content (Web 1.0) to Internet communities built around user-generated content (Fournier and Avery 2011; $\mathrm{Li}$ et al. 2014). Customers are no longer passive receivers of information; they are now co-creators and conduits for brand messages (Kozinets et al. 2010; Mahrous and Abdelmaaboud 2017).

From a marketing perspective, research indicates that creating bonds between the consumer and the brand offers stability to the brand (Madupu and Cooley 2010; Mao 2010; Sasmita and Mohd Suki 2015), and consumers who involve themselves with brand communities exhibit higher levels of brand loyalty (Brodie et al. 2013; Morgan-Thomas and Veloutsou 2013). Accordingly, Fournier and Avery (2011) suggest that in today's Internet-driven 
environment leveraging web 2.0 connectedness to facilitate the sharing of brand information in an OBC is a viable brand management strategy.

The vitality of an OBC is reliant on its informational content and social relationships (Chiu et al. 2006; Zhou et al. 2013), and the ongoing success of an OBC is dependent on having members actively involved in the community with a strong sense of belonging to the community and the brand (Bagozzi and Dholakia 2002; Wirtz et al. 2013; Zhang and Luo 2016). Furthermore, the bond between the consumer and the brand is deepened through interaction with other brand loyal members within the community (Millán and Díaz 2014). For example, Naylor et al. (2012, p. 106) suggest "seeing similar others supporting a brand will lead to greater affinity for the brand". OBCs act as an intermediary between customers and brands, with successful OBCs having the potential to increase brand-related consumer behaviour, such as brand loyalty, brand recognition, positive word of mouth and purchase intention (Mahrous and Abdelmaaboud 2017). All are positive outcomes that organisations and marketers strive to achieve (Andersen 2005; Casaló et al. 2011; Kuo and Feng 2013).

In OBCs, social capital is a construct that defines the structural characteristics of the community. Social capital facilitates the flow of communication between members in the community and is said to play a significant role in cultivating users' sense of belonging (Meek 2016; Zhao et al. 2012) and participative behaviour (Li et al. 2014; Sheng and Hartono 2015). According to Lee et al. (2011, p. 226) "the structural properties of a brand community can have an impact on relationship maintenance and, in turn, brand building". Therefore, social capital in an OBC is essential to the ongoing success of the community through improving the quality of the communication between its members, whilst adding value to the brand (Chiu et al. 2006; Muniz and O’Guinn 2001).

\section{Social capital}

Although definitions vary between scholars, there does seem to be a general understanding that social capital is derived from the structure of the relationships between people in a social environment, which creates collective productivity (Adler and Kwon 2002; Bourdieu 1986; Coleman 1988, 1990; Field 2008; Granovetter 1992; Jones and Taylor 2012; Nahapiet and Ghoshal 1998; Watson and Papamarcos 2002).

Opinions as to whether social capital is an asset from an individual perspective (Burt 1997), a collective level (Wasko and Faraj 2000), or both (Mathwick et al. 2008), and the beneficial outcomes it provides have caused much debate depending on the researcher's frame of reference.
For example, from an organisational perspective, the research suggests that an accrued level of social capital in business communities enhances career success (Adler and Kwon 2002; Burt 1992), lowers turnover rates (Burt 1992), reduces transaction costs (Nahapiet and Ghoshal 1998; Watson and Papamarcos 2002) and strengthens supplier relations (Baker and Obstfeld 1999). Furthermore, Nahapiet and Ghoshal (1998, p. 260) attributed social capital to the overall success of organisational communities. Despite varying views, there is general agreement that social capital theory is founded on the principle of "by making connections with one another and keeping them going over time, people are able to work together to achieve things that they either could not achieve by themselves or could only achieve with great difficulty" (Field 2008, p. 1).

Another dynamic in the discourse of community discussed in the literature are the elements that represent the construct of social capital. Past studies have argued that conceptualisation can be achieved more effectively by separating the facets of social capital into three clusters (Nahapiet and Ghoshal 1998; Tsai and Ghoshal 1998). For example, social capital embodies three dimensions: structural, relational and cognitive, all of which relate to a number of different aspects of the construct.

- The relational dimension refers to the type of association based on a history of interactions. This includes the closeness of the individuals, the trust they share, their obligations and expectations and how committed they are to the relationship (Granovetter 1992; Nahapiet and Ghoshal 1998). There is general agreement that social trust and reciprocity are a good representation of this aspect of social capital (DeFilippis 2001; Huysman and Wulf 2005; Jones and Taylor 2012; Nahapiet and Ghoshal 1998; Watson and Papamarcos 2002). In brand communities, reciprocity is likened to moral responsibility (Muniz and O'Guinn 2001) and is one of the core attributes of a genuine community as opposed to a generic group. The trust element of social capital is essential in an OBC as consumer to consumer word-ofmouth (WOM) communication is central to the success of the community. Members provide reviews and advice about commercial products or brands. Therefore, communities with a culture based on social trust ensure that the information shared is considered more reliable than a direct promotion by the brand owner (Kozinets et al. 2010).

- The cognitive dimension relates to the norms of the community or the values that members share and the common language they use with each other (Granovetter 1992; Nahapiet and Ghoshal 1998). These elements of social capital are predominantly referred to as a shared language and a shared vision (Huysman and 
Wulf 2005; Jones and Taylor 2012; Watson and Papamarcos 2002). Furthermore, in brand-affiliated communities, a shared vision relates to the consciousness of kind that members exhibit (Muniz and O'Guinn 2001), whilst a shared language is akin to the shared rituals and traditions demonstrated by members, both of which are indications of a genuine community (Muniz and O'Guinn 2001).

- The structural dimension represents the impersonal configuration of linkages between members of a group (Granovetter 1992): the ties that bind their relationships, the strength of their ties and the frequency of their interactions (Jones and Taylor 2012; Liao and Chou 2011; Nahapiet and Ghoshal 1998). In an organisational environment, the structural dimension of social capital is referred to as network ties; however, in an OBC context, social capital is embedded in the structural network of weak ties on a community level (Nahapiet and Ghoshal 1998). Network ties therefore represent stronger individual-level relationships that are an outcome of relational and cognitive social capital (Muniz and O'Guinn 2001; Shah et al. 2001).

Theorists suggest that in a community environment, accumulation of social capital is affected by the strength of interpersonal ties within the community (Coffé and Geys 2007; Granovetter 1973; Jones and Taylor 2012; Shah et al. 2001). An additional dynamic has subsequently been identified in the social capital construct that refers to either bridging social capital or bonding social capital (Coffé and Geys 2007; Granovetter 1973; Pinho 2013; Williams 2006). Bridging social capital relates to social groups where relationships are common between individuals from very different backgrounds, such as the weak ties found in brand communities (Granovetter 1973; Muniz and O'Guinn 2001; Shah et al. 2001), whilst bonding social capital refers to relationships between close friends or family, known as strong ties (Granovetter 1973).

Social groups based predominantly on weak ties provide more opportunities for individuals to widen their social networks, and therefore the number of people they grow to trust and engage with (Granovetter 1973, 1983). This was supported by Putnam (2000) who concluded that members of heterogeneous communities have higher levels of general trust than members of a homogenous group, a phenomenon explained by the diversity of a heterogeneous group who interact with people from a wide range of cultures and demographics and therefore learn to trust a variety of different people (Granovetter 1973, 1983; Nahapiet and Ghoshal 1998). In contrast, people with strong ties tend to have the same ideologies or interests and are therefore homogenous, a trait that makes trusting outsiders difficult and inhibits the accumulation of social capital (Granovetter 1973, 1983; Putnam 2000). A more compromising view is that in practice, many groups include both bridging and bonding functions, but the structural dimension of social capital leans towards either one or the other (Norris 2002).

Brand communities have been considered examples of heterogeneous communities, because they represent a "form of human association situated within a consumption context" (Muniz and O'Guinn 2001, p. 426), where members from diverse backgrounds with weak ties are brought together by a shared interest in a specific brand. The structure of the relationships in brand communities encourages interaction between members, which represents the bridging function of social capital (Coffé and Geys 2007; Granovetter 1992). Through active participation in the community, some members develop strong network ties with others as they discover commonalities between them over and above a shared interest in a particular brand. This indicates that the bonding function of social capital also applies in brand communities (Coffé and Geys 2007; McAlexander et al. 2002; Muniz and O'Guinn 2001).

In Granovetter's (1983) review of work directly testing the hypotheses of his 1973 paper "The Strength of Weak Ties", there appears to be agreement that weak ties generate momentum to spread information further afield. Therefore, social systems such as OBCs need weak ties to spread information efficiently. OBCs give individuals who are very different from each other culturally and socially, the opportunity to share information in a neutral setting (Naylor et al. 2012). Cultural diffusion is possible as ideas from small cohesive groups open to sharing are distributed to other groups via weak ties (Granovetter 1983). The values, norms and trust that represent social capital in an OBC mean that members, although unknown to each other, see themselves as part of a collective who attribute meaning to their shared interest in a specific brand. Therefore, social capital facilitates regular communication between members with weak ties (participative behaviour). Furthermore, communities with an accrued level of social capital have the capacity to create a sense of belonging between members and the community as well as to each other (Zhao et al. 2012).

Although there are multiple competing definitions and measures of social capital, there appears to be general accord that social capital is a multidimensional community-level construct that underlies the relational base of a community and affects the quality of the interaction between members (Coleman 1988; Granovetter 1992; Jones and Taylor 2012; Nahapiet and Ghoshal 1998; Watson and Papamarcos 2002). The literature also suggests an accrued level of social capital fosters an attachment to the community, prompts collective action between members, increases participation in the community and 
encourages long-term commitment (Coleman 1988; Granovetter 1992; Jones and Taylor 2012; Kleinhans et al. 2007).

Consequently, given the important influence social capital has on a community, understanding social capital within an $\mathrm{OBC}$ environment and the role it plays in building strong OBCs has significant value. Insights into these benefits provide marketers with the opportunity to enhance an organisation's reputation and must be considered critical in building strong brand equity.

\section{Methodology}

As this field of research is dynamic and constantly changing, the literature surrounding it requires frequent updating. Consequently, qualitative data provide a snapshot of contemporary practices within these communities and are useful in providing insights into this fast changing environment (Kozinets 2002). Gaining an understanding of naturally occurring behaviour involving information searches and interactive communication between consumers is of great significance to researchers particularly as the world evolves in the digital era (Adjei et al. 2010; Alavi et al. 2011; Avery 2007; Brodie et al. 2013; Chan and Li 2010).

Therefore, to examine the multidimensional construct of social capital in OBCs, a qualitative study was used consisting of two phases. Part A involved observation of several OBCs using a netnographic approach, and part B consisted of a series of focus groups designed to support the observational data and gain further insights into individual members' behaviour in today's online environment.

\section{Part A—netnography}

Netnography, sometimes referred to as digital ethnography or virtual ethnography, is a faster, more efficient and in most cases less expensive means to gather data than traditional ethnography and is specifically designed to study online consumer behaviour (Adjei et al. 2010; Alavi et al. 2011; Avery 2007; Brodie et al. 2013; Chan and Li 2010; Cova and Pace 2006; Kozinets 2002; Mathwick et al. 2008; Pongsakornrungsilp and Schroeder 2011). Netnography provides researchers with a comprehensive insight into member interaction in a virtual environment (Bartl 2011; Medberg and Heinonen 2014) and is considered an appropriate, effective and unobtrusive means of gaining rich, insightful information regarding OBCs.

The current study used a non-participative netnographic approach (Avery 2007; Brodie et al. 2013; Chan et al. 2014; Cova and Pace 2006; Cova et al. 2015; Mathwick et al. 2008), and for this project, the most suitable OBCs for analysis were those with a consumer orientation towards a brand, product type or lifestyle. In order to identify the online communities suitable for this study, the research initially conducted a broad and thorough computer search of the World Wide Web. More than one hundred communities were identified and then assessed for appropriateness for further analysis based on recommended criteria, such as their topic focus, accessibility, popularity and diversity from each other (Amine and Sitz 2004; Chan and Li 2010; Kozinets 2002).

Three global communities were selected for netnographic investigation based on the objectives of the study. They were:

- Vogue.com.au (Vogue)—a fashion and lifestyle magazine brand community;

- Avonfriendsforum.co.uk (Avon)—a cosmetics brand forum; and

- Bodybuilding.com (bodybuilding) - a fitness and health community. The Bodybuilding forum is centred around people who identify as bodybuilders (personal brand) and subsequently exhibit the characteristics of a genuine brand community.

The three sites were chosen for further analysis based on recommendations by Kozinets (2002) that careful selection of one or very few sites is sufficient for netnography data collection purposes. Three communities were included in this study to allow for comparative analysis (Adjei et al. 2010). The sites were chosen because they were very different from one another, both in population size and product type, had a specific topic focus (a magazine brand, a cosmetics company and bodybuilding, respectively), were easily accessible and well-populated, therefore fitting the criteria previously outlined. For example, the Avon community, although popular, was relatively small compared to Vogue and Bodybuilding who both had substantial membership bases. Each community attracted very different types of people, negating any consistencies that may arise from observing communities with similar member profiles (Zikmund et al. 2007, p. 322). Furthermore, membership to these communities did not require ownership or proof of purchase of a brand or product, thereby allowing for easy access.

The researcher registered as a member of each community, as registration was deemed necessary in order to gain full access to member profiles and archival posts and threads. Data were then collected from each site on membership numbers, posting frequencies and general topics of interest within each of the communities; an important procedure, since variances between the general structures and cultural environments of each community, has a significant effect on members' social behaviour (Amine and Sitz 2004; Kozinets 2002). This initial fieldwork provided background information about each 
community and could be drawn upon for inferences regarding participative behaviour across a selection of different OBCs.

The data collection process involved observation of members in each community whilst drawing upon the findings in the literature to guide the collection of relevant data (Brodie et al. 2013; Neuman 2006). The core of the data collection process constituted the interactions between members (Amine and Sitz 2004), and thousands of conversation threads in the three communities were observed and recorded over a four-month period. The researcher logged on daily to keep up to date with new posts and observe community participation. Member activity was recorded after each login, along with field notes of interesting conversation threads and recurring themes. Reflective field notes for each community were recorded to ensure subtexts, pretexts and emotional nuances were not missed (Kozinets 2002). Sites were also revisited after a 1-year period in order to provide comparative data relating to growth in member populations, postings and any updates to the site. Open coding was then performed on the collected data (Neuman 2006).

The open coding process involved reading through the data and grouping statements from the individual communities related to each concept. Although a deductive categorisation approach was utilised in this study, emergent categories were also taken into consideration when deemed relevant to the research (Cova and Pace 2006; Spiggle 1994). Axial coding was used to review and examine coded groups, and through an iterative process, ideas and themes were organised to identify the key concepts found in the data. Selective coding then involved scanning through the field notes and selecting cases to illustrate the different themes in the context of each online community (Neuman 2006, p. 463).

The information gathered from the communities (Vogue, Avon and Bodybuilding) over the four-month period was subsequently drawn together to identify patterns and relationships between the data from each community. Information was added at a later stage to indicate the rate of growth of each community over an extended period of time. The key objective of this stage (Part A) of the study was to gather information from discussion threads in a range of brand-related OBCs in order to contextualise the concepts outlined in the literature and explore any new themes that emerge.

\section{Part B-focus groups}

A series of focus groups were also conducted to build on the information derived from the literature and the netnography. Focus groups provided the opportunity to have a more intimate dialogue with participants of OBCs. This face-to-face communication, through open discussion with members from a range of $\mathrm{OBCs}$, was important to clarify the researcher's interpretation of the observations made through the netnography observation method (Part A) (Kitzinger and Barbour 1999, p. 75). As illustrated in "Appendix", the three focus groups conducted for this study included 20 members from a diverse range of OBC's. Socio-demographic characteristics of the focus groups participants are presented in Table 1. The structure of the focus groups encouraged participants to openly discuss issues of interest and relevance, with other members of the group able to interject and contribute their opinions to the topic under discussion (Stewart et al. 2007). This freeflowing style of conversation replicates the interactive
Table 1 Focus group participants sociodemographics

\begin{tabular}{lllll}
\hline & \multicolumn{2}{l}{ Focus groups } & Total $(n=20)(\%)$ \\
\cline { 2 - 4 } & $1(n=6)(\%)$ & $2(n=5)(\%)$ & $3(n=9)(\%)$ & \\
\hline Age & & & & \\
$18-24$ & 0 & 40.0 & 100.0 & 55.0 \\
$25-40$ & 83.3 & 40.0 & 0 & 35.0 \\
$40+$ & 16.7 & 20.0 & 0 & 10.0 \\
Gender & & & & \\
Male & 66.7 & 80.0 & 44.4 & 60.0 \\
Female & 33.0 & 20.0 & 55.6 & 40.0 \\
Occupation & & & & 65.0 \\
Student & 33.3 & 40.0 & 100.0 & 5.0 \\
Manager & 0 & 20.0 & 0 & 15.0 \\
Lecturer & 33.3 & 20.0 & 0 & 5.0 \\
Admin. & 33.3 & 0 & 0 & 5.0 \\
Scientist & 0 & 20.0 & 0 & \\
\hline
\end{tabular}


dialogue used by members in OBCs, an added advantage of using a focus group setting for this research.

Focus group participants were recruited from posters, flyers, email and word of mouth from Australian universities. As an incentive potential, respondents were advised that if they were eligible to participate in the focus groups, they would receive a $\$ 30$ gift card on completion of the session. Each focus group was video recorded, and tapes were transcribed for audio and visual data. Thematic content analysis was used to identify recurrent themes or constructs throughout the transcripts from each focus group (Redman-MacLaren et al. 2014). This process involved open coding followed by axial coding in order to recognise themes that occurred repeatedly on an individual and group scale (Breen 2006). A review of the data indicates that saturation point was reached on opinions about relevant topics. The trustworthiness of the data was confirmed via triangulation by researcher audits (Belk et al. 1989).

Triangulation is one of the leading techniques used to strengthen the credibility and trustworthiness of qualitative research (Belk et al. 1989). In this study, triangulation was utilised through the use of different data-capturing methods, in the form of netnographic observations followed by focus groups. This allowed the researcher to view the concepts from different perspectives and removed any possibility of bias that may arise from using a single data source (Neuman 2006). The use of different data-capture methods in this study also allowed for varying depths of immersion in the subject and a wider perspective on the research problems (Belk et al. 1989).

\section{Findings and insights}

\section{Netnography}

Observation of posts and discussion threads by members of the Vogue, Bodybuilding and Avon communities produced an abundance of insightful data related to member behaviour in OBCs. Common themes that support the existence and the importance of social capital within these communities emerged, and the dimensions used to define social capital of shared vision, shared language, social trust and reciprocity could all be effectively applied in this instance (Liao and Chou 2011; Nahapiet and Ghoshal 1998; Meek 2016). Comparative analysis of the three communities also indicates that regardless of the focus of the community, members are driven to participate in forums based on both the need for information and a desire to socialise. This finding is consistent with Zhou et al. (2013, p. 6) who found that "For visitors who have consumed the brand, they perceive information and social relationships derived online as equally important. Thus, both informational value and social value function to attract them and transform them into members". As social capital facilitates interaction within an $\mathrm{OBC}$ and usability and sociability are critical to the ongoing success of an OBC, these findings suggest social capital plays a significant role in the success of an $\mathrm{OBC}$.

\section{Community type}

Observation of the three OBCs revealed the focus of each community had a direct effect on the type of people the community attracted and the manner in which they conversed with each other. Although each community had terms and conditions in place, member behaviour differed between communities. These variances relate to the brand the community represents. For example, the following conversations taken from the Bodybuilding site are examples of the antisocial contingent in this forum. The posts include colloquial slang and derogatory statements, and although not representative of the whole community, they were prolific enough to be considered significant. The moderator's post is a reflection of the extent of this issue.

******** downstairs having a party and screaming at the top of their lungs at one am. Knock there and ask politely to keep it down. They keep doing it. If it were just a bit of loud music it wouldn't bother me so much but these $* * * * * * * *$ must be taught a lesson. $* * * * *$ that $*$ (BB \#22).

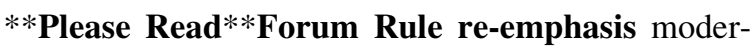
ators will be cracking down on hate speech, general bashing and illegal activity discussion such as -Racist, sexist, or bigoted comments or slurs in any form (including images). • Offensive, disgusting, aggressive, lewd, profane, or derogatory language, posts, pictures, or PM's •E-fighting, excessive arguing, or harassment of other users. Discussion of illegal activities (United States laws apply). This includes theft, paedophilia, rape, incest, murder. I know you all have the ability to discuss these issues without the hate talk, help us out by nixing it please (BB \#11).

Additionally, there are many threads that start off as a conversation and degenerate into a full blown argument where the tone is aggressive and often insulting.

If you knew anything about the Clintons then you would change your tune but seeing as you're an idiot (BB \#6).

I'd hang $\mathrm{u}$ with that $* * * * * * * *$ scarf IRL u limp wristed $147 \mathrm{lb}$ beta (BB \#5). 
Doubt you would even be able to reach my scarf, $* * * * * *(\mathrm{BB} \# 6)$

Although the administrative team in the Bodybuilding forum attempted to manage the site efficiently, there were such a vast number of members who contributed thousands of posts every day, and it became almost impossible to manage member behaviour effectively. Furthermore, the image portrayed by the Bodybuilding community is based on a culture associated with masculine, anti-authoritative characteristics, which attracts a small number of people who display a level of antisocial behaviour (Lhotáková 2012).

In direct contrast, the Vogue community had a very strict and efficient moderating team in place. In line with the reputation of their brand, they ensure conversations are strictly limited to friendly discussions related only to the sub-categories provided, and when interactions stray, moderators interject with a reminder of the rules, as demonstrated by the following post:

Please read the forum rules pertaining to the Beauty section (applicable to all of the sections on Vogue forum, but they are specific to issues in Beauty sections, including Hair, Skincare \& Fragrance and Makeup). Please ensure that you read other forum rules as well, because no topic that is prohibited in one section can be discussed anywhere on Vogue forum (Vogue \#1).

The tone and subject matter contained in the Vogue messages are illustrative of the standards expected of members in the Vogue community. Rigid terms and conditions and consistent moderation of the forum are factors designed to ensure strict adherence to the rules. This strategy is clearly aligned with upholding the organisation's respectable brand image.The Avon forum revealed a significant percentage of members who were Avon representatives, and accordingly, the majority of messages were dominated by their concerns. The lack of heterogeneity of community membership meant posts were often product focused and did not demonstrate participative behaviour with only one moderator post over the fourmonth period.

Just a quick reminder to say that The Lounge is for both Representatives and customers. It is a board where we can go off-topic, catch up on gossip, share latest news, and discuss recent trends. If Reps want help or want to talk about an Avon Rep related issue-please post this in Representative Talk (Avon \#3).

Well said! (Avon \#25).

I cannot find Representatives Talk??? (Avon \#26).
From a community perspective, both the Vogue and Bodybuilding forums attracted very different members based on the type of brand they represent. However, the majority of posts exhibited compliance with the rules put in place by the administrative team. This implies the members of these communities shared the same vision for the community as a whole (Liao and Chou 2011). Furthermore, in the Bodybuilding community, the common use of expletives illustrates a shared language between members, which gives them a sense of assimilation with the community. Both these traits are indicative of a community culture with an accrued level of social capital.

\section{Social capital}

Observation of posts and discussion threads between members in the Vogue forum, the Bodybuilding community and to a lesser degree the Avon forum provides strong support for the theory that the elements associated with social capital can effectively be applied to a range of OBCs. These findings are further discussed below.

\section{Shared language}

An important aspect associated with being part of an online community is having a shared language, as this gives members a sense of belonging to the community and sets them apart from outsiders (Muniz and O'Guinn 2001; Nahapiet and Ghoshal 1998). There is also evidence to suggest a shared language increases the efficiency of communication amongst members with similar knowledge (Adler and Kwon 2002; Nahapiet and Ghoshal 1998). In OBCs, knowledge sharing often involves sharing brandrelated information (Liao and Chou 2011); the example below is representative of thousands of similar posts and threads contributed by members to each forum, indicating a shared language with regard to designer brands and products:

I love my Ferragamos! I have both the Varinas and a pair of vintage loafers, which I both purchased from eBay. If you go down this route, you have to be aware of fakes-there's plenty of them on eBay! (Vogue \#31).

Great minds think alike! They're comfy, look great and last a very long time!

The likes of Saks and Neiman Marcus stock Ferragamo. They deliver internationally and are cheaper than Ferragamo shoes at full price at David Jones or Ferragamo boutiques (Vogue \#32).

Another aspect associated with a shared language is the use of specific terms related to either a brand type or interest. 
The Bodybuilding forum provided a large variety of evidence to support the use of a shared language between members, demonstrating their collective knowledge of the bodybuilding culture. These excerpts from a number of conversation threads support the literature, where the use of common vocabulary in OBCs has been shown to make the exchange of information more possible (Adler and Kwon 2002; Jones and Taylor 2012; Liao and Chou 2011).

I'd repeat three weeks before deloading to ensure it wasn't a case of poor diet/rest this past week but it requires checking to make sure your diet and sleep are in order for next week else you'll just trap yourself in this cycle (BB\#4).

Thanks for the response, weird thing is that last week I actually did a deload where I decreased the weight for each exercise by 55\% hoping that it would rest my body and allow me to lift the weights easier but that wasn't the case, this week I felt like the weight was heavier and I had a harder time (BB\#3).

I think your underestimating how much your biceps and triceps will grow from just compound exercises, but if you prefer working biceps and triceps directly $2 \times$ a week you can definitely do so, have (BB \#5).

Too heavy a deload. And I would try to bust the plateau two or three weeks before dropping the 10\% just to make sure it just wasn't a weak week (BB \#6).

Just trying to get some info on the differences between the EFS racks (collegiate) and the racks purchased through Williams Strength (BB \#75).

At the risk of becoming the RC shill...if you are leaning towards the EFS, you might want to look at the Rae Crowther Pro Gold half rack (if you haven't already) (BB\#76).

\section{Shared vision}

In online community behaviour, shared vision refers to the beliefs and norms members share with regard to the purpose of the community and reflects what members consider the forum represents (Field 2008; Liao and Chou 2011; Tsai and Ghoshal 1998). The significance of a shared vision in an online community is its ability to bring members together and encourage ongoing participation and a sense of belonging (Best and Krueger 2006; Chi et al. 2009; Jones and Taylor 2012; Liao and Chou 2011). The following conversation thread from the Vogue forum provides an example of members' shared vision for the community. Conversations across the three sites also demonstrated members' voluntary compliance with the rules enforced by moderators, which emphasises their shared vision.

Vogue IS about what is beautiful and fantastic. It's a magazine that has made millions selling a dream/ aspirations to people around the world. Open up any magazine and it's about fashion, beauty and lifestyle (Vogue \#8).

I agree, it's what a fashion magazine is supposed to be about (Vogue \#9).

I wouldn't want the board bogged down with people's relationship issues-this isn't Cosmopolitan or Seventeen or the Australian equivalent (Vogue \#10).

\section{Social trust}

Social trust is an integral element of social capital and is especially relevant to $\mathrm{OBCs}$ as it removes feelings of uncertainty and suspicion related to posting messages in an online environment (Chi et al. 2009). A culture of social trust encourages open discussion and reduces concerns members have about sharing information about themselves (Mathwick et al. 2008). The level of social trust accrued in a community is based on a history of positive interactions and reciprocal behaviour and develops over time through regular interaction with others in the community (Best and Krueger 2006). The following discussion highlights the relationship between trust and a sense of belonging to a community of people who care about each other.

Apologies if this topic is not allowed, but do any voguettes have any tips on moving forward from the loss of a loved one? Not looking for suggestions to speak to counsellors/psychologist/psychiatrist etx. Just after things or resources which have helped (Vogue \#30).

Mindfulness may help-especially if the grief starts to cause depression of anxiety. There are lots of books out there on this as well as short courses $\odot$ (Vogue \#31).

One of the resource sites, such as Grieflink, offers invaluable information on grief and bereavement (Vogue \#32).

Thank you ladies. My mum has just died and I am feeling so sad (Vogue \#30).

A more commercial aspect of trust in OBCs is related to the trust people place in product reviews provided by individual members as opposed to the company's advertising of its product or brand (The Nielson Company 2010). Research indicates it is important for companies in today's competitive environment to provide a platform where customers can 
access product knowledge from a credible source (Cunniffe and Sng 2012). Previous research suggests recommendations by friends and opinions posted online are the most trusted forms of advertising globally, with seven out of ten consumers surveyed putting their trust in the opinions of other customers who post information online (The Nielson Company 2010). Bodybuilding.com takes advantage of this trend by encouraging members in the Bodybuilding community to promote the brands they sell on their website. This encourages a co-creative culture within the community that brings members closer together (Carlson et al. 2008; Hatch and Schultz 2010). At the end of the four-month observational period, over 400,000 product reviews had been contributed to the forum. These findings support Kozinets et al. (2010) Network Co-Production model that recognises consumers as co-producers of brand value and meaning. Influencers in the Bodybuilding community share their opinions about specific brands creating a flow of word-ofmouth (WOM) communication between members. In the Bodybuilding forum, the reviews are considered valuable to the community as they are from individual members who share a social identity with each other (Zhao et al. 2012). Peer consumers are much more likely to share brand-related information with people they feel have an affinity with the same brand (Muniz and Schau 2005).

\section{Reciprocity}

Vogue and Bodybuilding forum members regularly posted requests for help or advice. The reliability and consistency of members' replies indicate that these communities have a reciprocal culture. In contrast, the Avon community exhibited little reciprocity, as evidenced by the lack of replies to a number of posts. The bearing this has on participative behaviour and sense of belonging is reflected in an increased number of members to the Vogue and Bodybuilding forums over the 4 months of observation, and the low level of participative behaviour demonstrated in the Avon community over the same period. Vogue members increased by 75 per month and posts went up by an average of 5617 per month. Bodybuilding demonstrated phenomenal growth with an increase of 80,000 new members and over 920,000 posts per month. In contrast, Avon had very little interaction and only increased by an average of nine new members and 34 posts per month.

These findings support the theory that members in OBCs are more likely to participate when they know members are happy to provide help and advice when needed (Best and Krueger 2006; Liao and Chou 2011; Mathwick et al. 2008). Reciprocity is a key factor for enhancing the sociability of OBCs and fundamental to their ongoing sustainability (Preece 2001) as demonstrated in the example below.
I am on the market for a new purse (either a Prada wallet or YSL wallet) and was wondering the best place to buy (Vogue \#20).

Check out bluefly.com! They have some great deals on their website (Vogue \#21).

I buy a lot of my designer brands from Saks. They have a good range of Prada wallets and YSL wallets (Vogue \#22).

If you can hold off for a couple of months, the midyear sales start late May/early June. I would jump onto Saks as soon as they start (Vogue \#32).

The Bodybuilding forum also demonstrated a reciprocal culture. In this community, posts frequently requested advice on buying exercise equipment or the use of supplements. Replies were timely and often quite technical and complicated, demonstrating a high level of support between members.

Guys can you increase your 1rm for DL without training super heavy? I mean can you train with high reps of 225lbs and still increase my $1 \mathrm{rm}$ (396lbs at the moment)?? Any ideas (BB \#48).

It is that stress that you are looking for. That is the stimulus that prompts adaptation (growth.) In short, no, you have to lift heavy to go heavy. Is that really even a question? I could be wrong, but that is just my 2c's (BB \#49).

Get on the hudson deadlift program sir (BB \#50).

What I'm hoping for is I could train with 225 for more and more reps and then only max out heavy deads once every couple of months. If my lifts go from12 reps@225 to 15-16 reps @ 225 that must have a difference on my 1 rep max? (BB \#48).

I think that suggested weight of less than $60 \%$ of your $1 \mathrm{RM}$ is too little. You don't have to go to near max levels all the time but I think $70-80 \%$ of your 1RM is a much better weight range to train in if you want to increase your 1RM (BB \#53).

Members of the Avon community displayed a lack of reciprocity, which over time appears to have affected levels of participative behaviour in the community. For example, observation of the Avon community identified a member (Avon \#6) who, over a period of 6 weeks, became so disillusioned with the site that she left the company and advertised her product in the community forum. After receiving no response to her messages, the member (Avon \#6) listed a number of items for sale, including an Avon starter pack of cosmetics, and a week later she was no longer listed as a member. This is indicative of a lack of accrued social capital 
in this forum, demonstrated by a lack of reciprocity between members and the absence of a shared vision. Whilst the community did exhibit signs of a shared language related to product knowledge, this can be attributed to a shared interest in the Avon brand rather than the culture of the community.

\section{Focus groups}

In these interviews, social capital was considered a community-level influence and the questions were designed to elicit the respondents' personal views of the social capital elements within the community. Findings from the focus group support the relevance of social capital in these communities and highlight the important role it plays in building a successful OBC.

\section{Shared language}

Respondents were asked to talk about the use of a shared language in their community and whether they thought it impacted on their involvement. The breadth of the topic elicited a variety of observations, yet several similarities emerged across all the focus groups to confirm the overall significance of shared language in $\mathrm{OBC}$ environments. A further theme to emerge suggested shared language has a positive impact on the network ties members develop. Several views were articulated about the way in which people converse in OBCs and how language similarities, based on background or culture, drew people together, resulting in the development of friendships. This is consistent with Yang and $\mathrm{Li}$ (2016) who advocate that a strong shared language offers a common code and meaning that other members feel obligated to respond to.

In our community we have shortcuts for moves in the game; it's our own language really (R\#8).

We are from everywhere, I speak to a lot of Maori's in my community cos' we speak the same language, if they don't get what we're about they go talk to another group like them (R\#15).

When you're in a game you don't have time to spell stuff out so you say stuff that's quick, it's the same in the forum we use shorthand when we talk (R\#13).

I can tell by the way they talk if they are around my age or not, and the friends I've got are all like me, we like the same clothes, we have stuff in common (R\#19).

\section{Shared vision}

Community culture established around a shared vision provides members with a basis from which mutually acceptable relationships can develop (Jones and Taylor 2012) and where members feel freer to exchange information (Tsai and Ghoshal 1998). With this in mind, respondents were asked to give an example of how a shared vision affected their participative behaviour and sense of belonging to their community. In the first focus group, it became apparent that respondents did not fully understand what a shared vision represented, thereby limiting relevant data from this group. The question on shared vision was reconfigured for the subsequent groups in order to clarify the concept. Responses from the two remaining focus group sessions revealed the majority of respondents felt their community had a belief system in place that was reassuring for members. This is consistent with previous research that found a shared vision reduces misunderstandings (Tsai and Ghoshal 1998), and those who identified an association between social capital and comfort levels with regard to sharing private information (Maksl and Young 2013).

In our forum everyone's a Tigers fan, so we're on the same team and we all want our team to win! Is that having a shared vision? (R\#4).

In the community I'm in now we all seem to want the same thing, we want to talk about the game and share strategies. In the other one I was in everyone was out for what they could get, they were in it for the wrong reasons so I left (R\#11).

I like to be in touch with other likeminded people (R\#8).

When I go on line I find there are lots of people in the same position as me (R\#12).

\section{Social trust}

Discussions on the topic of social trust created extensive interaction in each of the focus groups; however, the predominant theme across all sessions was the trustworthiness of the information shared between members of the community. Similarly, Zhao et al. (2012, p. 576) found "through repeated interactions between members, and between an individual and the Virtual Community (VC), trust in other members of the virtual community gradually develops". Social trust also relates to network ties, as it appears the more trust members place in the community as a whole, the more likely they are to make friends within the community.

I trust more the word-of-mouth from community members than the advertisers, I trust that person because they're a community member (R\#19).

If you can't trust the people in the community it puts you off posting comments, you don't want a whole lot of replies to your threads that are negative (R\#14).

I've got to know loads of people I now consider as friends, I wouldn't have even thought about sharing 
personal stuff with people if I didn't trust the community not to turn on me (R\#19).

Participants also claimed that trust builds up over time, and communities are only as trustworthy as the information they provide. Members who consistently posted information or advice received a large number of positive comments and became well known in the community. As members provided more solid, useful information over time, the more the overall community was considered to be trustworthy. These findings correspond with Mahrous and Abdelmaaboud (2017, p. 244) who posit that "a significant positive relationship exists between emotional trust and consumers' participation in online brand communities". This finding also highlights the importance of the trust element of social capital in facilitating continued interaction between members in the community known to be a critical to success factor in OBCs (Mahrous and Abdelmaaboud 2017; Zhao et al. 2012). Respondents also discussed the role of moderators with regard to monitoring discussion threads to ensure members adhered to the rules and did not post offensive or derogatory comments. Members' compliance with the rules of a community not only relates to the trustworthiness of the community, but also reflects the members' shared vision. Therefore, although the responses obtained were related to a question of social trust, they also apply to a shared vision in the community. One participant revealed cancelling their membership to another community due to the "nasty comments, and foul language" (R\#17) of other members. This prompted heated discussion about online etiquette:

If there's an argument online and someone is reposting someone else's work they are the first to get shut down (R\#18).

I don't mind the mods hanging around but when they start removing threads because they don't like the language, or the comments are too negative, that ****** me off ( $\mathrm{R \# 20).}$

They have to be strict or you get a whole load of trolls writing stupid posts (R\#16).
Reciprocity

Research indicates members in OBCs are more likely to participate if they know other members will provide help or advice when they need it (Best and Krueger 2006; Liao and Chou 2011; Mathwick et al. 2008). Focus group participants in this study were asked how they felt about the concept of reciprocity in relation to participation and to give examples. Their observations included both positive and negative examples, with an overall outcome suggesting OBCs are reliant on the reciprocal nature of their members for encouraging ongoing participation. There is also evidence to suggest the reciprocal nature of the community has an effect on members developing friendships within the community.

What determines why I stay on is the feedback I get (R\#10).

You start out helping each other with advice on which cards are better than others and spells and stuff, eventually you become friends it's a natural progression (R\#14).

\section{Discussion}

The primary objective of this study was to investigate the elements that represent social capital in an OBC environment, and to identify the potential benefits of communities with an accrued level of social capital. As illustrated in Fig. 1, the findings indicate that a shared language, a shared vision, reciprocity and social trust can effectively be applied to OBCs and that network ties, a sense of belonging and increased participative behaviour are positive outcomes of an accrued level of social capital in OBCs. As these outcomes are considered critical to the ongoing success of an OBC, social capital is key to their survival. Furthermore, elements of social capital facilitate effective transference of brand knowledge between consumers in OBCs (Chiu et al. 2006) which is known to influence brand loyalty behaviour and product adoption (Kozinets et al. 2010).

Fig. 1 Conceptual framework

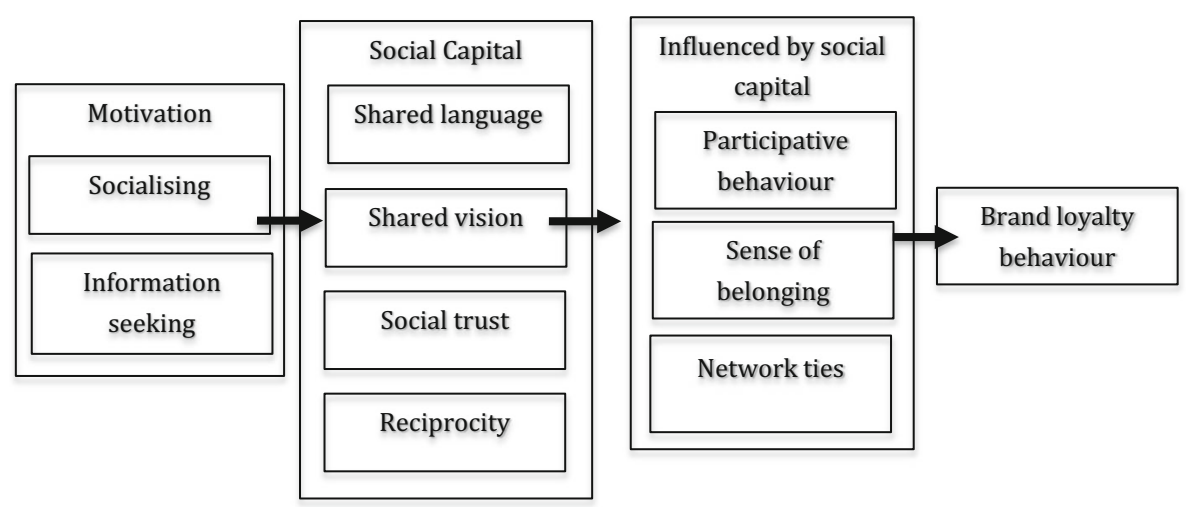


For example, members in the Bodybuilding forum used their own jargon to discuss workout regimes and their muscular development. They had similar views about how they wanted the forum to operate and spent time offering advice to each other on a number of subjects. There was also a level of trust regarding the brands and products members recommended, and members regularly wrote reviews on products they'd been asked to trial. Their honest opinions and detailed descriptions regarding the use of the product were of significant value to other members and clearly benefited the company. This practice is considered a form of co-creation between members and the brand owner (Hatch and Schultz 2010) and strengthens the interactions amongst members of OBCs (Carlson et al. 2008; Zaglia 2013).

In the Vogue and Avon communities, a shared language was demonstrated through members' knowledge and use of fashion- and beauty-related brand names. Discussions in the Vogue forum also indicated members had embraced the Vogue brand image and what it represents. Members were inclined to offer advice when needed and exhibited a high level of social trust, as evidenced by some of the more intimate conversations observed. In contrast, the only social capital element identified in the Avon forum was a shared language, which is not surprising given the majority of members were Avon representatives rather than consumers of the brand. The negative aspect of social capital for a new member or member who is yet to develop or understand the community's shared language, is their inability to converse via this common language with the community. As a result, they could feel alienated or excluded from the group. Furthermore, according to Portes (1998), the strong ties that connect group members can also lead to the rejection of outsiders.

Over the four-month period of the study, both the Vogue and Bodybuilding forums substantially increased their numbers of new members and numbers of new posts contributed. In direct contrast, over the same period, only a small number of new members joined the Avon forum and very few posts were added. Furthermore, when the researcher revisited the forums a year after the conclusion of the netnography, both the Vogue and Bodybuilding forums were experiencing ongoing success, whereas the Avon forum was no longer active.

Posts and discussion threads contributed to the Vogue and Bodybuilding forums indicate network ties between members exist in both communities and have a positive effect on the sense of belonging members develop with one another and the community. This is evident from the social tone used by respondents, the terms of friendship included in conversations and their demonstrated interest in each other's circumstances.

Observations of all three OBCs in this study indicate that the elements associated with social capital are clearly relevant in OBCs. Furthermore, the findings strongly support the contention that concepts discussed in this study can also effectively be applied to OBCs. For instance, both the Vogue and Bodybuilding communities were involved in informational exchange whilst also maintaining a high level of sociability, apparent from the technical content of the conversations and the popularity of posts of a more social nature. In the Avon community, socialising was not a priority, leading the researchers to conclude that consistent with the Usability and Sociability framework (Preece 2001) where OBCs have an equal share of information seekers and socialisers, they are more likely to achieve ongoing success and sustainability.

An interesting theme to emerge from the focus group discussions is the potential relationship between the different aspects of social capital and the development of network ties. A number of respondents expressed the view that members of OBCs are more likely to befriend others who use a similar language to their own. They also mentioned a solid base of social trust and reciprocity is fundamental to developing long-term network ties.

\section{Theoretical contributions}

Given that online brand communities are a major communication medium and there has been a growth in their adoption by organisations and customers, understanding the dynamics of their success is critical to the development of online brand communities and ultimately brand equity. The brand is the foci in an OBC, and social capital enhances the quality of communication between members in the community. Furthermore, people who form a stronger relationship and engagement with the brand are more likely to generate higher brand satisfaction, brand trust, commitment, loyalty and ultimately advocacy (Wirtz et al. 2013). Therefore, understanding how the elements of social capital enhance the user experience in OBCs will advance previous research in this field.

The results of our study demonstrate the utility of applying social capital theory to enhance online brand community success. Fundamentally, for an online brand community to be successful, members must actively engage with the community. Social capital facilitates this engagement by enhancing the quality of communication amongst members in the community through the four elements of social capital: shared language, shared vision, social trust and reciprocity. Furthermore, social capital enriches the network ties amongst members, which is critical for building loyalty and equity with the brand. Shared language is an integral aspect for developing a sense of belonging, which positively influences the development of network ties amongst members and the community. A shared vision enables the exchange of information within an OBC by facilitating ongoing participation and a sense of belonging. Social trust and reciprocity are also key elements to 
develop in an $\mathrm{OBC}$, as they are instrumental in enhancing open communication, reducing concerns about sharing personal information and increasing the credibility of the information shared in the community.

Findings from this study support the applicability of social capital theory to the online brand community context. It reinforces the need to foster social capital development to ensure ongoing interaction and participation between members in the community, which is a critical success factor for an OBC. This new research presents contextualisation of social capital in OBCs through indepth qualitative analysis providing gainful insights for academics and practitioners. From a theoretical stance, investigating social capital in the context of OBCs addresses a significant gap in the literature, as there is very little research of a qualitative nature that explores the existence and benefits of each element of social capital specifically in an $\mathrm{OBC}$ context.

Understanding this context becomes important as it provides insights into how brands are created and the way this is changing in today's business environment. As most organisations seek to develop a strong digital footprint to increase reach and build their brand, the relationship between firm and consumer is changing.

Promotional campaigns that built brands on a business to consumer dyad are no longer as efficient, or as far reaching, as a more network created online approach (Schau et al. 2009). Brands now are built through co-creation, where value and brand equity are developed by networks of users. This study provides insights into this shifting paradigm and the new components needed to build brands in a contemporary business setting, where the networks of OBCs are used to co-create value and where social capital is a critical element in the success of these networks.

\section{Practical contributions}

The findings of this study suggest that to succeed over the long term, OBCs need to fulfil both social and informational needs for members and visitors to the community. OBCs also require a core of active members who contribute interesting user-generated content to keep existing members involved and attract new members (Kamboj and Rahman 2017). Primarily though, this research found that the elements that represent social capital as a multidimensional construct are key to the ongoing success of OBCs.

As existing research indicates that members who have developed network ties in the community, participate regularly and have a sense of belonging to the community exhibit increased brand loyalty behaviour (Loureiro et al. 2017), managers of OBCs must embrace the brand's attributes by encouraging the use of a shared language, emphasising the values the brand represents, and developing a culture based on social trust and reciprocity to ensure sustainability.

This study shows that consumers develop long-lasting relationship ties with members in OBCs through social interaction and transference of brand knowledge. Furthermore, the elements associated with social capital are key drivers of the consumer-generated information exchange. Understanding how the elements of social capital such as a shared language, a shared vision, reciprocity and social trust enhance the users experience in an $\mathrm{OBC}$ will give marketers and brand managers guidance when developing strategies to enhance their brand. It is not enough to build an $\mathrm{OBC}$ and expect members to co-create brand identity through interaction in the OBC (Mahrous and Abdelmaaboud 2017). Managing the relational structure of the community so that members develop a sense of belonging, build network ties and enjoy actively participating in the community is the key to their success.

Kozinets et al. (2010) suggest the type of person and their narrative dictates the content and audience for an individual's blog. In this study, consistent with Kozinets et al. (2010), it was found that in OBCs the type of brand determines the values and norms of the community. The nature of the word-of-mouth communication differs between each of the OBCs. This suggests that from a practical perspective, marketers need to consider that although communities with an accrued level of social capital encourage knowledge-sharing behaviour, the type of brand has a significant influence on the tactics they can use for community-based marketing promotions.

In conclusion, this study supports the claim that social capital is an important element and driver of successful OBCs. Consequently, understanding the dynamics of social capital and contextualising the elements that make up this construct is important if managers and marketers are to harness the consumer power associated with these growing virtual communities.

\section{Compliance with ethical standards}

Conflict of interest The authors declare that they have no conflict of interest.

Open Access This article is distributed under the terms of the Creative Commons Attribution 4.0 International License (http://crea tivecommons.org/licenses/by/4.0/), which permits unrestricted use, distribution, and reproduction in any medium, provided you give appropriate credit to the original author(s) and the source, provide a link to the Creative Commons license, and indicate if changes were made.

\section{Appendix}

See Table 2. 
Table 2 Focus group sample characteristics

\begin{tabular}{|c|c|c|c|c|}
\hline Respondent & Age & Gender & Occupation & Community type \\
\hline \multicolumn{5}{|c|}{ Focus group 1} \\
\hline $\mathrm{R} \# 1$ & $25-40$ & Male & Student & Cameras (Canon) \\
\hline $\mathrm{R} \# 2$ & $25-40$ & Male & Lecturer & Automobiles (Ford) \\
\hline $\mathrm{R} \# 3$ & $25-40$ & Female & Administrator & Medical (Mennings disease) \\
\hline $\mathrm{R} \# 4$ & $25-40$ & Male & Lecturer & Football (Richmond Football Club) \\
\hline $\mathrm{R} \# 5$ & $25-40$ & Female & Student & Cooking (Jamie Oliver) \\
\hline R\#6 & $40+$ & Male & Administrator & Gaming (Castle Age) \\
\hline \multicolumn{5}{|c|}{ Focus group 2} \\
\hline $\mathrm{R} \# 7$ & $18-24$ & Female & Lecturer & Books (Linda) \\
\hline R\#8 & $25-40$ & Male & Scientist & Gaming (Minecraft) \\
\hline $\mathrm{R} \# 9$ & $18-24$ & Male & Student & Gaming (Battlefield) \\
\hline R\#10 & $25-40$ & Male & Student & 4 wheel drive vehicles (Hilux) \\
\hline R\#11 & $40+$ & Male & Manager & Gaming (PlayStation) \\
\hline \multicolumn{5}{|c|}{ Focus group 3} \\
\hline R\#12 & $18-24$ & Female & Student & Medical (Beyond Blue) \\
\hline R\#13 & $18-24$ & Female & Student & Gaming (World of Warcraft) \\
\hline R\#14 & $18-24$ & Male & Student & Gaming (Magic the Gathering) \\
\hline R\#15 & $18-24$ & Male & Student & Entertainment (Sony) \\
\hline R\#16 & $18-24$ & Female & Student & Gaming (Grand Theft Auto) \\
\hline R\#17 & $18-24$ & Female & Student & Books (Amazon) \\
\hline R\#18 & $18-24$ & Male & Student & Gaming (PlayStation) \\
\hline R\#19 & $18-24$ & Female & Student & Fashion (LookBook) \\
\hline $\mathrm{R} \# 20$ & $18-24$ & Male & Student & Gaming (PlayStation) \\
\hline
\end{tabular}

\section{References}

Adjei, M.T., S.M. Noble, and C.H. Noble. 2010. The influence of $\mathrm{C} 2 \mathrm{C}$ communications in online brand communities on customer purchase behaviour. Journal of the Academy of Marketing Science 38(5): 634-653.

Adler, P.S., and S. Kwon. 2002. Social capital: Prospects for a new concept. Academy of Management Review 27(1): 17-40.

Alavi, S., V. Ahuja, and Y. Medury. 2011. An empirical approach to ECRM-increasing consumer trustworthiness using online product communities. Journal of Database Marketing \& Customer Strategy Management 18(2): 83-96. https://doi.org/10.1057/ dbm.2011.12.

Alden, D.L., J.B. Kelley, J.B. Youn, and Q. Chen. 2016. Understanding consumer motivations to interact on brand websites in the international marketplace: Evidence from the US. China, and South Korea Journal of Business Research 69(12): 5909.

Algesheimer, R., U. Dholakia, and A. Herrmann. 2005. The social influence of brand community: Evidence from European car clubs. Journal of Marketing 69(3): 19-34.

Amine, A., and L. Sitz. 2004. How does a virtual brand community emerge? Some implications for marketing research. Paris: University Paris.

Andersen, P.H. 2005. Relationship marketing and brand involvement of professionals through web-enhanced brand communities: The case of Coloplast. Industrial Marketing Management 34(1): 39-51.

Apple Support Communities. 2018. APPLE support forum. https:// discussions.apple.com/welcome. Accessed 6 July 2018.
Avery, J. 2007. Saving face by making meaning: The negative effects of consumers' self-serving response to brand extension. Doctoral dissertation, Harvard Business School.

Backhaus, K., M. Steiner, and K. Lugger. 2011. To invest, or not to invest, in brands? Drivers of brand relevance in B2B markets. Industrial Marketing Management 40: 1082-1092.

Bagozzi, R.P., and U.M. Dholakia. 2002. Intentional social action in virtual communities. Journal of Interactive Marketing 16(2): $2-21$.

Baker, W.E., and D. Obstfeld. 1999. Social capital by design: Structures, strategies, and institutional context. In Corporate Social Capital and Liability, ed. R.T.A. Leenders and S.M. Gabbay, 88-105. Boston: Kluwer.

Baldus, B.J., C. Voorhees, and R. Calantone. 2015. Online brand community engagement: Scale development and validation. Journal of Business Research 68(5): 978-985.

Bartl, M., Jawecki, G., Stönner, J.H. and Gastes, D. 2011. Review of a Decade of Netnography Research: Implications for Future Social Media Analysis. In Conference Proceedings ESOMAR 3D Digital Dimensions, pp. 1-12.

Belk, R.W., M. Wallendorf, and J.F. Sherry. 1989. The sacred and the profane in consumer behaviour: Theodicy on the odyssey. Journal of Consumer Research 16(1): 1-38.

Best, S.J., and B.S. Krueger. 2006. Online interactions and social capital: Distinguishing between new and existing ties. Social Science Computer Review 24(4): 395-410.

Bourdieu, P. 1986. The forms of capital. In Handbook of Theory and Research for the Sociology of Education, ed. J.G. Richardson, 241-258. New York: Greenwood.

Breen, R.L. 2006. A practical guide to focus-group research. Journal of Geography in Higher Education 30(3): 463-475. 
Brodie, R.J., A. Ilic, B. Juric, and L. Hollebeek. 2013. Consumer engagement in a virtual brand community: An exploratory analysis. Journal of Business Research 66(1): 105-114.

Burt, R.S. 1992. Structural Holes: The Social Structure of Competition. Cambridge: Harvard University Press.

Burt, R.S. 1997. The contingent value of social capital. Administrative Science Quarterly 42(2): 339-365.

Carlson, B.D., T.A. Suter, and T.J. Brown. 2008. Social versus psychological brand community: The role of psychological sense of brand community. Journal of Business Research 61(4): 284.

Casaló, L.V., C. Flavián, and M. Guinalíu. 2011. Antecedents and consequences of consumer participation in on-line communities: The case of the travel sector. International Journal of Electronic Commerce 15(2): 137-167.

Chan, K., and S. Li. 2010. Understanding consumer-to-consumer interactions in virtual communities: The salience of reciprocity. Journal of Business Research 63(9/10): 1033.

Chan, T.K.H., X. Zheng, C.M.K. Cheung, M.K.O. Lee, and Z.W.Y. Lee. 2014. Antecedents and consequences of customer engagement in online brand communities. Journal of Marketing Analytics 2(2): 81-97.

Chi, L., W. Chan, G. Seow, and K. Tam. 2009. Transplanting social capital to the online world: Insights from two experimental studies. Journal of Organizational Computing and Electronic Commerce 19(3): 214-236.

Chiu, C.M., M.H. Hsu, and E.T. Wang. 2006. Understanding knowledge sharing in virtual communities: An integration of social capital and social cognitive theories. Decision Support Systems 42(3): 1872-1888.

Coffé, H., and B. Geys. 2007. Participation in bridging and bonding associations and civic attitudes: Evidence from Flanders. Voluntas: International Journal of Voluntary and Nonprofit Organizations 18(4): 385-406.

Coleman, J.S. 1988. Social capital in the creation of human capital. American Journal of Sociology 94: S95-S120.

Coleman, J.S. 1990. Foundations of Social Theory. Cambridge, MA: Harvard University Press.

Cova, B., and S. Pace. 2006. Brand community of convenience products: new forms of customer empowerment-the case "My Nutella The Community". European Journal of Marketing 40(9/ 10): 1087-1105

Cova, B., S. Pace, and P. Skalen. 2015. Brand volunteering: Value cocreation with unpaid consumers. Marketing Theory 15(4): 465-485. https://doi.org/10.1177/1470593115568919.

Cunniffe, N., and M. Sng. 2012. ADMAP: For Decision Makers in Advertising, Marketing, Media, Planning \& Research. London: Reed Publ. Serv.

DeFilippis, J. 2001. The myth of social capital in community development. Housing Policy Debate 12(4): 781-806.

De Souza, C.S., and J. Preece. 2004. A framework for analyzing and understanding online communities. Interacting with Computers 16(3): 579-610.

Dholakia, U., R. Bagozzi, and L. Pearo. 2004. A social influence model of consumer participation in network- and small-groupbased virtual communities. International Journal of Research in Marketing 21(3): 241-263.

Fang, Y., and D. Neufeld. 2009. Understanding sustained participation in open source software projects. Journal of Management Information Systems 25(4): 9-50.

Field, J. 2008. Social Capital, 2nd ed. London: Taylor and Francis Ltd.

Find a Nike + Run Club. 2018. Find a run club. https://www.nike. com/us/en_us/c/running/nike-run-club/find-run-club Accessed 6 July 2018.

Fournier, S., and J. Avery. 2011. The uninvited brand. Business Horizons 54(3): 193-207.
Granovetter, M.S. 1973. The strength of weak ties. American Journal of Sociology 78(6): 1360-1380. https://doi.org/10.1086/225469.

Granovetter, M. 1983. The strength of weak ties: A network theory revisited. Sociological Theory 1: 201-233. https://doi.org/10. 2307/202051.

Granovetter, M. 1992. Problems of explanation in economic sociology. In Networks and Organizations: Structure, Form, and Action, ed. N. Nohria and R. Eccles. Boston, MA: Harvard Business School Press.

Hatch, M.J., and M. Schultz. 2010. Toward a theory of brand cocreation with implications for brand governance. Journal of Brand Management 17(8): 590-604. https://doi.org/10.1057/bm. 2010.14.

Hau, Y.S., B. Kim, H. Lee, and Y.G. Kim. 2013. The effects of individual motivations and social capital on employees' tacit and explicit knowledge sharing intentions. International Journal of Information Management 33(2): 356-366.

Huysman, M., and V. Wulf. 2005. The role of information technology in building and sustaining the relational base of communities. The Information Society 21(2): 81-89.

Islam, J.U., Z. Rahman, and L.D. Hollebeek. 2018. Consumer engagement in online brand communities: A solicitation of congruity theory. Internet Research 28(1): 23-45. https://doi.org/ 10.1108/IntR-09-2016-0279.

Jones, T., and S.F. Taylor. 2012. Service loyalty: Accounting for social capital. Journal of Services Marketing 26(1): 60-75.

Kamboj, S., and Z. Rahman. 2017. Understanding customer participation in online brand communities. Qualitative Market Research: An International Journal 20(3): 306-334.

Kitzinger, J., and R.S. Barbour. 1999. Developing Focus Group Research: Politics, Theory, and Practice. London: Sage Publications.

Kleinhans, R., H. Priemus, and G. Engbersen. 2007. Understanding social capital in recently restructured urban neighbourhoods: Two case studies in Rotterdam. Urban Studies 44(5): 1069-1091. https://doi.org/10.1080/00420980701256047.

Kozinets, R.V. 2002. The field behind the screen: Using netnography for marketing research in online communities. Journal of Marketing Research 39(1): 61-72.

Kozinets, R., K. de Valck, A. Wojnicki, and S. Wilner. 2010. Networked narratives: Understanding word-of-mouth marketing in online communities. Journal of Marketing 74(2): 71.

Kuo, Y., and L. Feng. 2013. Relationships among community interaction characteristics, perceived benefits, community commitment, and oppositional brand loyalty in online brand communities. International Journal of Information Management 33(6): 948-962

LEGO ideas community. 2018. LEGO ideas. https://ideas.lego.com/. Accessed 6 July 2018.

Lee, H., D. Lee, C. Taylor, and J. Lee. 2011. Do online brand communities help build and maintain relationships with consumers? A network theory approach. Journal of Brand Management 19(3): 213-227.

Lhotáková, M. 2012. The growing brand equity and brand valueThe learnings from most valuable brands. Studia commercialia bratislavensia 5(19): 434-448.

Li, G., X. Yang, and S. Huang. 2014. Effects of social capital and community support on online community members' intention to create user-generated content. Journal of Electronic Commerce Research 15(3): 190-199.

Liao, S., and E. Chou. 2011. Intention to adopt knowledge through virtual communities: posters vs lurkers. Online Information Review 36(3): 442-461.

Loureiro, S., T. Gorgus, and H. Kaufmann. 2017. Antecedents and outcomes of online brand engagement. Online Information 
Review 41(7): 985-1005. https://doi.org/10.1108/OIR-08-20160236.

Lu, X., C. Phang, and J. Yu. 2011. Encouraging participation in virtual communities through usability and sociability development: An empirical investigation. ACM SIGMIS Database 42(3): 96-114.

Madupu, V., and D. Cooley. 2010. Cross-cultural differences in online brand communities: An exploratory study of Indian and American online brand communities. Journal of International Consumer Marketing 22(4): 363-375.

Mahrous, A., and A. Abdelmaaboud. 2017. Antecedents of participation in online brand communities and their purchasing behavior consequences. Service Business 11(2): 229-251. https://doi.org/10.1007/s11628-016-0306-5.

Maksl, A., and R. Young. 2013. Affording to exchange: social capital and online information sharing. Cyberpsychology, Behavior, and Social Networking 16(8): 588-592.

Mao, J. 2010. Customer brand loyalty. International Journal of Business and Management 5(7): 213-217.

Mathwick, C., C. Wiertz, and K. De Ruyter. 2008. Social capital production in a virtual P3 community. Journal of Consumer Research 34(6): 832-849.

McAlexander, J., J. Schouten, and H. Koenig. 2002. Building brand community. Journal of Marketing 66(1): 38-54.

Medberg, G., and K. Heinonen. 2014. Invisible value formation: A netnography in retail banking. International Journal of Bank Marketing 32(6): 590-607.

Meek, S.A. 2016. Understanding influences on the critical-to-success factors in online brand communities. Doctoral dissertation, Edith Cowan University, Australia.

Millán, A., and E. Díaz. 2014. Analysis of consumers' response to brand community integration and brand identification. Journal of Brand Management 21: 254-272. https://doi.org/10.1057/bm. 2014.4.

Morgan-Thomas, A., and C. Veloutsou. 2013. Beyond technology acceptance: Brand relationships and online brand experience. Journal of Business Research 66(1): 21.

Muniz, A., and T. O'Guinn. 2001. Brand community. Journal of Consumer Research 27(4): 412-432.

Muniz, A.M., and H.J. Schau. 2005. Religiosity in the abandoned Apple Newton brand community. Journal of Consumer Research 31(4): 737-747.

Nahapiet, J., and S. Ghoshal. 1998. Social capital, intellectual capital, and the organizational advantage. Academy of Management Review 23(2): 242-266.

Naylor, R.W., C.P. Lamberton, and P.M. West. 2012. Beyond the "like" button: The impact of mere virtual presence on brand evaluations and purchase intentions in social media settings. Journal of Marketing 76(6): 105-120.

Neuman, L. 2006. Social Research Methods, 6th ed. Boston: Pearson Education Inc.

Norris, P. 2002. The bridging and bonding role of online communities. The Harvard International Journal of Press/Politics 7(3): $3-13$.

Pinho, C.J. 2013. The e-SOCAPIT scale: A multi-item instrument for measuring online social capital. Journal of Research in Interactive Marketing 7(3): 216-235.

Pongsakornrungsilp, S., and J.E. Schroeder. 2011. Understanding value co-creation in a co-consuming brand community. Marketing Theory 11(3): 303-324.

Portes, A. 1998. Social capital: Its origins and applications in modern sociology. Annual Review of Sociology 24(1): 1-24. https://doi. org/10.1146/annurev.soc.24.1.1.

Preece, J. 2001. Sociability and usability in online communities: Determining and measuring success. Behaviour \& Information Technology 20(5): 347-356.
Preece, J. 2002. Supporting community and building social capital. Communications of the ACM 45(4): 37-39.

Putnam, R.D. 2000. Bowling Alone: The Collapse and Revival of American Community. New York: Simon and Schuster.

Redman-MacLaren, M., J. Mills, and R. Tommbe. 2014. Interpretive focus groups: A participatory method for interpreting and extending secondary analysis of qualitative data. Global Health Action 7(1): 25214. https://doi.org/10.3402/gha.v7.25214.

Sasmita, J., and N. Mohd Suki. 2015. Young consumers' insights on brand equity. International Journal of Retail and Distribution Management 43(3): 276-292. https://doi.org/10.1108/IJRDM02-2014-0024

Schau, H.J., A.M. Muñiz Jr., and E.J. Arnould. 2009. How brand community practices create value. Journal of Marketing 73(5): $30-51$.

Schouten, J.W., and J.H. McAlexander. 1995. Subcultures of consumption: An ethnography of the new biker. Journal of Consumer Research 22(1): 43-61.

Shah, D.V., N. Kwak, and R.L. Holbert. 2001. "Connecting" and "disconnecting" with civic life: Patterns of Internet use and the production of social capital. Political Communication 18(2): $141-162$.

Shah, S.K. 2006. Motivation, governance, and the viability of hybrid forms in open source software development. Management Science 52(7): 1000.

Shang, R., Y.C. Chen, and H.J. Liao. 2006. The value of participation in virtual consumer communities on brand loyalty. Internet Research 16(4): 398-418.

Sheng, M., and R. Hartono. 2015. An exploratory study of knowledge creation and sharing in online community: A social capital perspective. Total Quality Management and Business Excellence 26(1): 93-107.

Sicilia, M., and M. Palazón. 2008. Brand communities on the internet: A case study of Coca-Cola's Spanish virtual community. Corporate Communications: An International Journal 13(3): $255-270$

Singh, S., and S. Sonnenburg. 2012. Brand performances in social media. Journal of Interactive Marketing 26(4): 189-197.

Sloan, S., K. Bodey, and R. Gyrd-Jones. 2015. Knowledge sharing in online brand communities. Qualitative Market Research: An International Journal 18(3): 320-345.

Spiggle, S. 1994. Analysis and interpretation of qualitative data in consumer research. Journal of Consumer Research 21(3): 491-503.

Stewart, D.W., P.N. Shamdasani, and D.W. Rook. 2007. Theory and Practice. Focus Groups. Thousand Oaks: Sage Publications.

The Nielson Company. 2010. Social media dominates Asia Pacific internet usage, 17 September. http://blog.nielsen.com/nielsen wire/global/social-media-dominates-asia-pacific-internet-usage/. Accessed 6 July 2018.

Tsai, W., and S. Ghoshal. 1998. Social capital and value creation: The role of intrafirm networks. Academy of Management Journal 41(4): 464-476.

Wasko, M.M., and S. Faraj. 2000. "It is what one does": Why people participate and help others in electronic communities of practice? The Journal of Strategic Information Systems 9(2): $155-173$.

Watson, G.W., and S.D. Papamarcos. 2002. Social capital and organizational commitment. Journal of Business and Psychology 16(4): $537-552$.

Wirtz, J., A. den Ambtman, J. Bloemer, C. Horváth, B. Ramaseshan, J. van de Klundert, Z.G. Canli, and J. Kandampully. 2013. Managing brands and customer engagement in online brand communities. Journal of Service Management 24(3): 223-244. 
Williams, D. 2006. On and off the 'net: Scales for social capital in an online era. Journal of Computer Mediated Communication 11(2): 593-628.

Yang, X., and G. Li. 2016. Factors influencing the popularity of customer-generated content in a company-hosted online cocreation community: A social capital perspective. Computers in Human Behavior 64: 760-768. https://doi.org/10.1016/j.chb. 2016.08.002.

Zaglia, M.E. 2013. Brand communities embedded in social networks. Journal of Business Research 66(2): 216-223.

Zhang, M., and N. Luo. 2016. Understanding relationship benefits from harmonious brand community on social media. Internet Research 26(4): 809-826.

Zhao, L., Y. Lu, B. Wang, P.Y.K. Chau, and L. Zhang. 2012. Cultivating the sense of belonging and motivating user participation in virtual communities: A social capital perspective. International Journal of Information Management 32(6): 574-588.

Zhou, Z., J. Wu, Q. Zhang, and S. Xu. 2013. Transforming visitors into members in online brand communities: Evidence from China. Journal of Business Research 66(12): 2438.

Zikmund, W., S. Ward, B. Lowe, and H. Winzar. 2007. Marketing Research, Asia Pacific ed. South Melbourne: Thomson Learning.

Stephanie Meek is a Lecturer in the field of Marketing and Business in the School of Business and Law, at Edith Cowan University. Her teaching areas of expertise include International Marketing, Retail Marketing, Business Research and Business Analytics. Her research interests include interactive Internet-based consumer behaviour, brand engagement, building brand equity in an online environment. Stephanie has comprehensive industry experience in management, marketing and advertising. Dr. Meek received her Ph.D. in Marketing from Edith Cowan University, Perth, Western Australia.
Madeleine Ogilvie is an Associate Professor in Marketing at Edith Cowan University and currently works as the Associate Dean Teaching and Learning in the School of Business. Her research interests are in the fields of semiotics, consumer research and visual methodologies where she has published and presented both nationally and internationally. Prior to working at ECU, Madeleine worked extensively in the pharmaceutical industry. She has consulted for both public and private organisations on many facets of marketing and management.

Claire Lambert is a Lecturer in the field of Marketing at Edith Cowan University. She specialises in the areas of branding and marketing communications in young children's and adult's responses. Her research includes consumer engagement and interactive customer/brand relationships; measuring brand equity and predicting brand preference; and consumer susceptibility and responses to advertising and sales promotion. Dr. Lambert has extensive industry experience in marketing and sales promotion within the quick service food and consumer goods industries. She received her Ph.D. in Marketing from the University of Western Australia.

Maria M. Ryan is an Associate Professor in Marketing and is currently Associate Head of the School of Business and Law at Edith Cowan University. Her research interests include the impact on consumption of individuals' attachment to their environment, using various research methods to examine consumption behaviour and tourism impacts. Maria has published competitive papers at the international and national level on consumer behaviour, brand management and methodological issues. In addition, she has worked extensively in the marketing research industry across both private, public and not-for-profit clients. 